Recebido em 23/03/2020 e aprovado em: 10/04/2020

\title{
O GLAM ROCK BRASILEIRO: MODA E COMPORTAMENTO ANDRÓGINO NA DÉCADA DE 1970
}

\section{THE BRAZILIAN GLAM ROCK: ANDROGINE FASHION AND BEHAVIOR IN THE 1970S}

Patrícia Marcondes de Barros'

\begin{abstract}
Resumo A presente pesquisa analisa Moda e comportamento relacionado à androginia do gênero musical Glam rock, surgido na Inglaterra no final dos anos 1960, como uma provocação à estética naturalista hippie. Por meio de pesquisa qualitativa de cunho bibliográfico documental (documentários, impressos alternativos de época e peças publicitárias), analisaremos num primeiro momento a estética andrógina inerente ao Glam Rock que ganhou visibilidade com astros a exemplo de David Bowie, Marc Bolan e Lou Reed. Posteriormente, perscrutaremos a referida estética no Brasil, expressa por artistas como Ney Matogrosso, Edy Star e o grupo teatral Dzi Croquettes que escandalizaram o público brasileiro em tempos de ditadura militar com suas performances viscerais e figurinos extravagantes, transcendendo as fronteiras entre o feminino e o masculino. O Glam rock criou uma identidade rebelde através do corpo e da androginia, subvertendo ideias estabelecidas na vida e na Moda.
\end{abstract}

Palavras-Chave: Androginia. Glam Rock. Moda.

Abstract: The present research analyzes Fashion and behavior related to the androgyny of the musical genre Glam rock, which emerged in England in the late 1960s, as a provocation to the hippie naturalistic aesthetic. Through qualitative research of documentary bibliographic nature (documentaries, alternative periodicals and advertising pieces), we will first analyze the androgynous aesthetics inherent in Glam Rock that gained visibility with stars such as David Bowie, Marc Bolan and Lou Reed. Subsequently, we will examine the aesthetics in Brazil, expressed by artists such as Ney Matogrosso, Edy Star and the theater group Dzi Croquettes who scandalized the Brazilian public in times of military dictatorship with their visceral performances and extravagant costumes, transcending the borders between the feminine and the male. Glam rock created a rebellious identity through the body and androgyny, subverting ideas established in life and in Fashion.

Keywords: Androgyny. Glam Rock. Fashion.

\footnotetext{
1 Professora no Departamento de História da Universidade Estadual de Londrina. Pós Doutora na linha de pesquisa "Literatura, Cultura e Tradução" (Universidade Federal de Pelotas-UFPEL), Doutora e Mestre em História pela Universidade Estadual Paulista. E-mail: patriciamarcondesdebarros@gmail.com
} 
BARROS, Patrícia Marcondes de. O Glam Rock brasileiro: moda e comportamento andrógino na década de 1970. Domínios da imagem, v. 13, n. 25, p. 65-88, jul./dez. 2019.

\section{Introdução}

O presente artigo2 tem como objetivo geral analisar os significados da Moda andrógina, relacionada ao gênero musical Glam Rock, que teve sua expressão no Brasil nas décadas de 1970 e 1980.

Surgido em momento posterior à contracultura hippie, o gênero Glam rock (abreviação de Glamour Rock, também chamado de Glitter Rock) pautou-se numa estética hedônica tida por muitos como decadente, produzindo música pop quando a linguagem do rock já se tornava para muitos, ultrapassada (GOFFMAN; JOY, 2007, p. 343):

[...] A estética Glam não dizia respeito a virtuosismo instrumental, e porque eles não se levavam muito a sério. As vestimentas andróginas espalhafatosas e intencionalmente deselegantes, sua bizarra teatralidade no palco e bissexualidade real ou falsa impressionavam (para aqueles que gostavam disso) ou era tão alienante (para os que não gostavam), que muitos estavam cegos para a alta qualidade de pelo menos parte do trabalho (GOFFMAN; JOY, 2007, p.343).

A questão da sexualidade se tornava o grande "parque de diversões do rock nos anos 70" (HERMAN APUDGOFFMAN; JOY, 2007, p.343) e a questão da androginia ganhou visibilidade por meio da teatralidade, excentricidade dos trajes (MAUS, 2016) e performances de seus principais expoentes internacionais, a exemplo de artistas como Marc Bolan, David Bowie, Elton John, lggy Pop, entre outros.

Apesar da provocação e do antagonismo em relação à estética hippie, esta foi de suma importância para o gênero Glam na discussão trazida pela contracultura 3 sobre a liberdade de expressão, partindo do corpo e suas

\footnotetext{
2Versão ampliada e revisada da comunicação publicada em anais, intitulada "A contracultura, o glam rock e a moda andrógina dos anos 70-80". III Seminário Internacional História do Tempo Presente, UDESC, 2017. ISSN 22374078.

3 De forma geral, entende-se historicamente como contracultura, o movimento social juvenil de caráter internacionalista relacionado às décadas de 60 e 70 que teve como mote a crítica à cultura dominante. Ganhou visibilidade e alcance no Brasil em fins da década de 60, inicialmente com o Tropicalismo e posteriormente, com a incorporação do caráter underground nas artes, na imprensa alternativa, na produção literária independente e na estética marginal, expressões de resistência frente ao momento de repressão ditatorial e de ressignificação do caráter identitário nacional. Conceitualmente e de forma perene, a contracultura floresce "sempre e onde quer que alguns membros de uma sociedade
} 
BARROS, Patrícia Marcondes de. O Glam Rock brasileiro: moda e comportamento andrógino na década de 1970. Domínios da imagem, v. 13, n. 25, p. 65-88, jul./dez. 2019.

vestes (entendidas também como meios comunicacionais de diferenciação e resistência, inerentes à contestação juvenil em curso) e da transcendência sexual com a androginia, compreendida por muitos, como a mutação e a evolução da espécie humana, ideia que desenvolveremos no decorrer do artigo. Imergia com a contracultura sessentista, uma nova sensibilidade, a do love peace, que fora expressa no comportamento de parte da juventude e na indumentária, com vestes, cabelos e adereços que comunicavam os novos tempos que ansiavam. Antagônicos aos românticos tardios da década de 60, os jovens da década seguinte, "submersos em sua própria individualidade, substituíram a ideia de luta coletiva por uma promiscuidade sem culpa" (GOFFMAN; JOY, 2007, p.343). Ícone do Glam rock, David Bowie se declarou à revista Rolling Stones em 1970 como um anti-hippie: "Eu quero estrangulá-los com seus colares!" (GOFFMAN; JOY, 2007, p.343).

Segundo Maus (2016), o gênero musical Glam Rock teve origem na Inglaterra entre o final dos anos 1960 e começo dos 1970, desnaturalizando os movimentos no corpo e na indumentária percebidos no estilo hippie, tornando-os excessivos e glamorosos.

[...] Em mais uma reação à simplicidade e aos temas pastorais do rock hippie e à seriedade do rock progressivo, surgiu um estilo que buscava ser glamoroso, divertido e teatral. O glam rock ou glitter rock trouxe cor, deboche e desempenhos cênicos para os palcos. Dançante, andrógino e extravagante, o glam rock nasceu com o trabalho de Gary Glitter, David Bowie, TRex e Roxy Music, na Grã-Bretanha, Kiss e do New York Dolls, nos Estados Unidos (ANAZ, 2013, p.52).

escolham estilos de vida, expressões artísticas e formas de pensamentos e comportamentos que incorporam o antigo axioma segundo o qual, a única verdadeira constante é a própria mudança. Sua marca é a fluidez de formas e estruturas, a perturbadora velocidade e flexibilidade com que surge, sofre mutação, se transforma em outra e desaparece" (GOFFMAN; JOY, 2007, p. 9). 
BARROS, Patrícia Marcondes de. O Glam Rock brasileiro: moda e comportamento andrógino na década de 1970. Domínios da imagem, v. 13, n. 25, p. 65-88, jul./dez. 2019.

A construção de sua estética pautava-se em referências que iam do surrealismo à ficção científica, como a exemplo do personagem andrógino ZiggyStardust ${ }^{4}$ de David Bowie que ficou eternizado como um alienígena rock star que aterrissa em um mundo predestinado a acabar em cinco anos.

No Brasil, a estética andrógina do Glam ganha expressão com artistas como Edy Star (Edivaldo Souza), o grupo musical Secos \& Molhados, Rita Lee \&Tutti Frutti, o grupo Made in Brazil e os membros do grupo teatral DziCroquettes, entre outros, que escandalizaram as "famílias tradicionais" com suas performances e indumentárias. Através do deboche, da liberdade de escolher ser (e se vestir), desafiaram as estruturas conservadoras sedimentadas da sociedade ditatorial brasileira.

Por meio de pesquisa qualitativa de cunho bibliográfico e documental (com a utilização de impressos alternativos de época, peças publicitárias, documentários), analisaremos num primeiro momento, o comportamento andrógino advindo da contracultura e apropriado pelo Glam Rock na década de 1970. Posteriormente, discutiremos a travessia ao Brasil desse gênero musical, estilo e Moda, com as performances viscerais e indumentárias extravagantes de seus protagonistas que transcendiam as fronteiras do entendimento de gênero: feminino e masculino. O Glam configurou-se como uma resistência estética, entendida segundo Pineda (2010) como o "transformar-se em arte - criar e inovar como forma de gerenciamento da vida, da liberdade, das relações, das subjetivações - tornar possível, por exercício de insistência, aquilo que não o era" (PINEDA, 2010, p. 6).

\section{"Children of the Revolution": Androginia, contracultura e Glam rock}

\footnotetext{
4The Rise And Fall Of Ziggy Stardust And The Spiders From Mars (1974) é um álbum conceitual de David Bowie que corresponde ao filme de mesmo nome. O álbum conta a história de Ziggy Stardust, um alienígena superstar do rock que junto de sua banda, The Spiders From Mars, são responsáveis por trazer esperança à humanidade através de sua música. Bowie incorpora a figura de Ziggy Stardust para falar sobre política, drogas e orientação sexual. O álbum documenta também o último show do Bowie personalizado de Ziggy Stardust, que foi retratado em 1998 através do filme Velvet Goldmine, baseado na cena Glam inglesa no período de 1971 a 1974 (Ornelas, 2018).
} 
BARROS, Patrícia Marcondes de. O Glam Rock brasileiro: moda e comportamento andrógino na década de 1970. Domínios da imagem, v. 13, n. 25, p. 65-88, jul./dez. 2019.

[...] Talvez os sexos sejam mais aparentados do que se pensa e a grande renovação do mundo talvez resida nisto, o homem e a mulher, libertados de todos os sofrimentos falsos, de todos os empecilhos, virão a procurar-se não mais como contrastes, mas sim como irmãos e vizinhos; a juntar-se como seres humanos. 0 problema dos sexos no eu (RILKE, 1971, p.11).

Bem, você pode pular e rebolar/Se for bom para sua mente/Bem, você pode torcer e gritar/Deixe tudo sair/Mas você não vai enganar os filhos da revolução (TYRANNOSAURUS REX, 1972). ${ }^{5}$

Na Moda, a androginia ganhou visibilidade em diferentes contextos, desde o estilo clean e masculino de Coco Channel nos anos 20 até os movimentos historicamente denominados como contraculturais, a exemplo da juventude hippie e em sua esteira, já na década de 1970, do Glam rock.

Para tratarmos do tema proposto, remetemo-nos ao momento anterior a este, com o movimento hippie dos anos 1960. Por meio da chamada Revolução Sexual proposta pela contracultura hippie, ganha visibilidade o conceito de androginia, tomado no aspecto comportamental e místico, expresso inicialmente através de shows de rock que delinearam de forma provocadora a estética Glam, reverberada posteriormente para outras esferas artísticas.

O termo contracultura, utilizado pela imprensa norte-americana para designar o fenômeno histórico hippie no mundo, ganhou significação política emergindo como uma resposta crítica frente às ilusões do capitalismo e do rigoroso sistema tecnocrático instaurado no mundo pós-guerra. A busca por uma existência autêntica levou parte da juventude envolvida com seu ideário a ampliar o conceito de política, estendendo-o ao corpo, ao comportamento dos indivíduos e à questão sexual. Acerca da sexualidade, discutiu-se sobre como as instituições (estado, escola e família, a exemplo) controlavam o corpo de forma autoritária. A ideia era transcender a questão sexual e romper com as dualidades geradoras dos conflitos e, consequentemente, das

5Well you can bump and grind/it is good for your mind/Well you can twist and shout/let it all hang out/But you won't fool the children of the revolution. Letra da música Children Of The Revolution (1972) de T. Rex (banda de rock inglesa conhecida como Tyrannosaurus Rex) escrita por Marc Bolan. 
neuroses. Para parte dessa juventude envolvida com a contracultura, não havia mais a ideia de sexo especializado, como postula Muraro:

[...] O jovem da Era Eletrônica não tem sexo especializado. A Era Eletrônica é a Era do andrógino. O unissex não é mais do que um sintoma físico de uma transformação mais profunda. $O$ machão tradicional reprimia a sensibilidade, assim como a mulher submissa reprimia a inteligência (MURARO, 1972, p. 7).

Rose Marie Muraro, uma das principais interlocutoras do Feminismo na perspectiva da Revolução Sexual em curso no Brasil, assinalou que na Era Eletrônica:

[...] o jovem não tem medo de viver, até as últimas consequências, a sua sensibilidade e a mulher atira-se em massa às atividades intelectuais, ficando assim esmaecida a milenar especialização sexual que dividiu o homem da mulher e os deixou sós" (MURARO, 1972, p. 7).

Foram vários os artigos escritos na imprensa alternativa brasileira repudiando a discriminação por gênero e opção sexual, colocando a androginia como a mutação da espécie. Em "Homem não é mulher, homulher. Mulher não é mulher, é mulhomem"(1972), entrevista publicada na revista alternativa "Bondinho" (1971-1974), Muraro enfatiza que o cerne da questão era ter manifestadas as duas essências (masculina e feminina) de forma equilibrada, fundidas em um só corpo, este então, andrógino.

Na referida entrevista é visível a influência que Muraro recebeu do antropólogo e crítico americano (de origem mexicana) Norman O. Brown, no concernente à ideia de superação da questão sexual, indo além do entendimento binário ("homem ou mulher"), geralmente apresentado como a normalidade (BARROS, 2017, p.98). Norman O. Brown é um dos pensadores que traduz a chamada "nova consciência", referenciado nos artigos da imprensa alternativa brasileira, a exemplo da revista de música e comportamento Rolling Stone (1972):

[...] Para Jung e Mircea Eliade, o símbolo do andrógino é um arquétipo do inconsciente coletivo, isto é, um símbolo-força que faz parte das estruturas psico-fisiológicas do homem. A gravura 
(uma das muitas que circularam na ldade Média) pode ser explicada assim: "O rei e a Rainha estão unidos em um só corpo de acordo com a concepção do livro do Gênesis: por isso deixará o homem seu pai e sua mãe e se unirá à sua mulher; e serão dois numa só carne". O andrógino pisando sobre um monstro de quatro cabeças e pés de águia. O monstro simboliza a matéria-prima dos alquimistas e a alma simboliza a alma. Como na gravura, a alma foi engolida pelo monstro, tendo somente os pés para fora, isso quer dizer que ela ainda não brotou das trevas da ignorância que a escondem (BROWN, 1972, p.45).

Na obra Love's Body (1966), Brown postula que só há um corpo e que este é andrógino, seus corpos múltiplos são aparentes e apesar disso, a unidade permanece sempre no inconsciente (tido como o "real"). A androginia é discutida no capítulo que trata da união de toda a humanidade num só corpo: "Almas, personalidades e egos são máscaras, espectros, escondendo nossa unidade como corpo. Só há um corpo" (BROWN, 1966, p.82) 6 .

Sustentando seus argumentos por meio da religião, Brown cita a Bíblia em Gênesis, para legitimar a natureza andrógina de Deus. Segundo sua interpretação: "Deus criou o homem à própria imagem, macho e fêmea" (BROWN, 1972, p.162). A androginia é reunificadora dos opostos, separados por nossa alienação psicológica fundamental, responsável pelos conflitos internos, neuroses e múltiplos desastres daí resultantes. A regeneração da espécie, segundo Brown, é tal qual a teologia cristã prescreve: "a ressurreição do corpo", ou seja, a plena atualização de todas as suas potencialidades circunscritas no corpo andrógino. Contudo, ressalta que a androginia não se refere intrinsecamente à bissexualidade, mas sim, como corpo sem um centro egóico; é um corpo místico, síntese da dualidade: "[...] Quem conhece o macho, no entanto adere ao que é da fêmea. Torna-se como a ravina, abrigando todas as coisas debaixo do cév; (Daí) a virtude eterna jamais escapar. Isto é retornar ao estado de infância" (BROWN, 1972, p.163).

\footnotetext{
${ }^{6}$ No original: [...] in the twentieth century, in this age of fission, we can split the individual even as we can split atom. Souls, personalities and egos are masks, spectres, concealing our unity as body. For it is as one biological species that mankind is one - the species-essence (Brown, 1966, p.82). Tradução livre.
} 
BARROS, Patrícia Marcondes de. O Glam Rock brasileiro: moda e comportamento andrógino na década de 1970. Domínios da imagem, v. 13, n. 25, p. 65-88, jul./dez. 2019.

Esse "retorno ao estado de infância", segundo Muraro em seu artigo intitulado "Feminismo e Androginia" (1972), tornava-se visível na perspectiva "do jovem que descobria a plenitude dos sentidos e da inteligência, recuperando a vida do corpo em todas as dimensões" (MURARO, 1972, p. 45), transcendendo as normatizações impostas pela cultura dominante.

Para Singer (1990) a androginia é uma realidade essencial da natureza humana que leva a um caminho no qual os papéis individuais e os modos de comportamento podem ser escolhidos, libertando-nos do que é considerado padrão (SINGER APUDMAUS, 2016, p.33). Neste sentido, o caráter andrógino da juventude contracultural subverte os padrões normativos e ganha visibilidade nas formas de expressão e diferenciação assinaladas por um estilo caracterizado pelo hedonismo, narcisismo e liberdade de escolher o que se quer ser. Revela-se assim o anseio ideológico de ruptura com os padrões estéticos vigentes.

[...] Totalmente feminino, nada rejeitas: abriga todos os relâmpagos e os compreendes, na compaixão, totalmente masculino, nada desejas: ofereces todos os relâmpagos, em doação atenta. Receber e dar, ativa e passivamente, é deixar que a dança de Shiva te atravesse, rompendo a cascadina do desespero e horror que também podes reconhecer, agora submersa na alegria amorosa que se manifesta. Mas esta treva brilha e se confunde com a luz (MACIEL, 1971, p. 11).

Nas décadas de 1960 e 1970, houve o surgimento de uma nova sensibilidade descentralizada, síncrona e polifônica que emergia e comunicava não mais apenas com as palavras, mas com o corpo - o olhar, o cabelo, as vestes unissex, confortavelmente largas e coloridas (BARROS, 2016 , p.162). A indumentária, neste contexto, remetia à influências do "passado/presente/futuro" indo além da ideia de temporalidade (BARROS, 2016, p.162), segundo astrólogos e futuristas, iniciava-se a Era de Aquarius na qual: "renasce tudo. (...) A linguagem não é mais aquela. Diz com o olho, com o cabelo, com a cor, com o sotaque, com o joint, com a macrobiótica, o sorriso, o incenso e a graça" (VICENTE, 1971, p. 9). 
BARROS, Patrícia Marcondes de. O Glam Rock brasileiro: moda e comportamento andrógino na década de 1970. Domínios da imagem, v. 13, n. 25, p. 65-88, jul./dez. 2019.

Essa nova sensibilidade delineada de forma assistemática pelo movimento hippie propiciou, segundo Giles Lipovetsky (2009), a ruptura com a ideia dualista de moda masculina e feminina, surgindo assim, o estilo unissex. Com o fim da utopia sessentista, no início dos anos 1970, o Glam Rock surge antagonizando o movimento anterior:

[...] Não surpreende que a desilusão possa ser libertadora. Já não se esperava que os desiludidos dos anos 60 fizessem a revolução da noite para o dia, e eles já não eram contidos pelas severas exigências antimaterialistas da ética do dropouthippie hiperespiritualista. Para fora das tendas e para dentro das boates. Que alívio do cacete! Alguns jovens decidiram vestir suas roupas para mergulharem em um período de sexualidade selvagem e entrega à festa. Uma nova cultura roqueira, chamada de glitter ou glam, foi a primeira rebelião contracultural contra o conformismo hippie e as expectativas de correção pública (GOFFMAN; JOY, 2007, p.340).

O Glam baseou-se no estilo de rock pré-hippie da subcultura Mod dândi inglesa de meados dos anos 1960 (GOFFMAN; JOY, 2007, p.340) mesclando música sofisticada (advinda do rock progressivo) com a cultura de massa Kitsch, perceptível nos cabelos multicores, unhas pretas, estampas de onça, um apelo imagético tecnológico e futurista com ombreiras, brincos emborrachados, suspensórios e cores pulsantes na maquiagem (que ganhavam destaque com cortes de cabelos curtos e simétricos para as mulheres) a exemplo, denotando extravagância e futurismo. No artigo publicado na revista Rolling Stone intitulado "Bowiemania", a questão da Moda e Arte estão intrinsecamente relacionadas às novas formas libertárias de ser/estar no mundo levados a tona com a contracultura andrógina. Bowie

\footnotetext{
7 Segundo Gruda (2017), os Mods, jovens da classe operária da Inglaterra, pós Segunda Guerra mundial, com poder de consumo, usaram a moda para construir um sentido de sua própria identidade pública, e até definindo suas próprias formas de pop arte, diante de uma indústria da moda que buscava impor o gosto através da pressão da publicidade e da mídia. Visualmente se caracterizaram pelas vestes andróginas, adotando muitos elementos do vestuário masculino, como calças, retas, sapatos baixos, cabelos bem curtos e pouca maquiagem. O estilo foca no "color blocking" (uma tendência que mistura cores vibrantes em um mesmo traje), no preto e branco e toques de amarelo vivo, laranja, rosa e cores pastéis. Os padrões geométricos foram utilizados, como a bandeira da Inglaterra, bolinhas e listras.
} 
afirma: "Eu me visto do meu jeito, sou extrovertido e estou na minha - que pode ser a sua, se você tiver coragem" (MICK TED, 1972, p. 9).

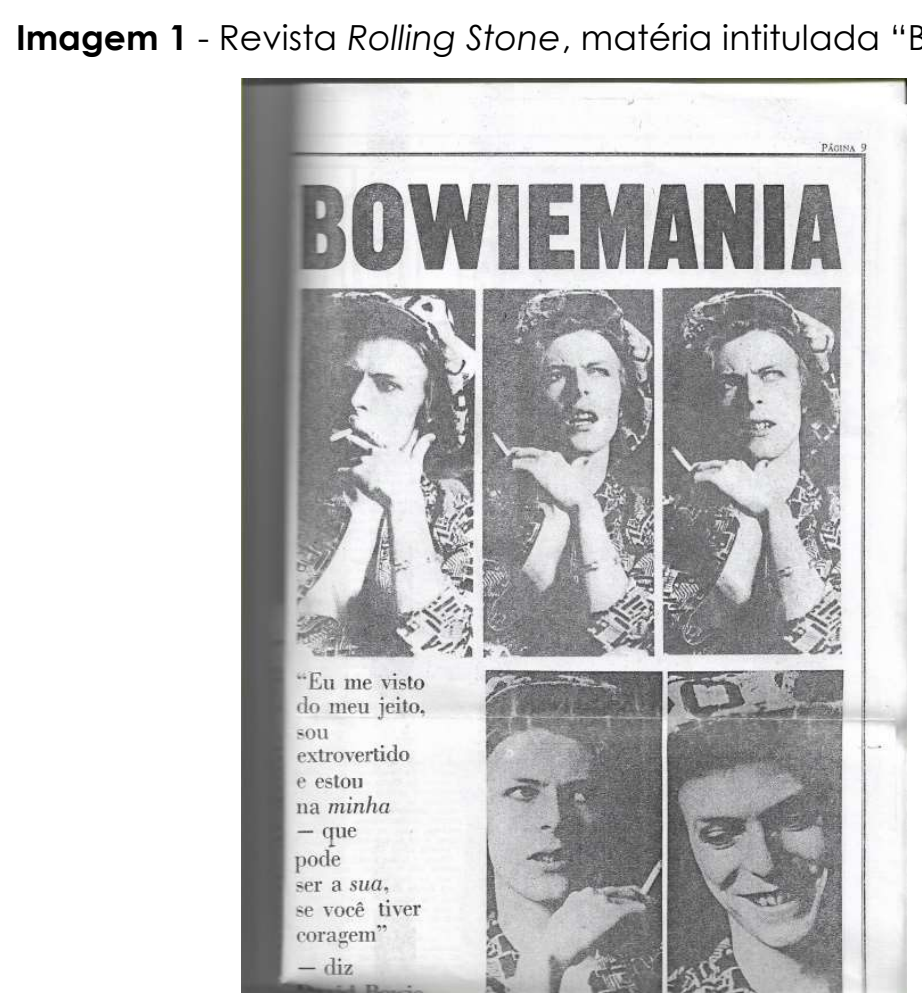

Fonte: Acervo pessoal

O Glam perceptível nas tendências da Moda atual ganhou vida nos palcos com os artistas do rock, alcançou as passarelas (em coleções como da Balmain e Paco Rabbane) e as ruas, a exemplo dos suspensórios, mulheres com gravatas, brincos emborrachados, tênis com estampas quadriculares, boinas e estampas de cores berrantes (quem viveu os anos 80 , com certeza lembrará).

A travessia do gênero musical e estilo de seus principais protagonistas "tropicais" escandalizaram o público brasileiro, em época denominada pelo jornalista Zuenir Ventura como de "vazio cultural" 8, caracterizada pela repressão advinda da ditadura militar, com o exílio de artistas e intelectuais. Em contraponto à guerrilha política, emergia a estética, com a rebeldia Glam no Brasil - rock e androginia entre plumas, paetês e derivados.

\footnotetext{
8 Zuenir Ventura utiliza-se do termo "vazio cultural" na revista Visão em 1971, localizando no
} Al-5 e na censura os principais fatores da "fossa generalizada" (DIAS, 2003, p.48). 


\section{Rebeldia "entre plumas \& paetês": A estética Glam na Moda e comportamento brasileiro}

[...] Em determinadas épocas a loucura e a realidade se unem e se tocam. O que é desumano e irracional é aceito com tranquilidade, o que ameaça por ser novo é controlado imediatamente, o que representa novos valores, novas aspirações é cerceado violentamente, o que eclode como a maior possibilidade do ser humano, a de poder criar livremente, não é permitido. O homem, então, volta-se para 0 plano individual, não podendo agir... Imagina, muitas vezes se embaraça em seus próprios labirintos (ARRABAL, 2005, p. 207).

[...] O que nós estamos precisando agora é de uma música que ressuscite todos os nossos pesadelos, um grupo com a noção perfeita da cloaca primitiva, que varra da consciência nossos sonhos medíocres, que nos liberte dessa hipnose chamada de civilização. Um conjunto e uma música que sejam um eletrochoque de aços implacáveis, grito nas cavernas da alma, gigante soluçante, anão em chamas, pedaço de sol na tribo, som perfurando a crosta dos sentados, vivo de paz, guerra de amor no veludo da goela (PIVA, 1972, p.13).

A travessia do estilo andrógino do Glam Rock ao Brasil ganhou visibilidade inicialmente através de artistas como Edy Star, Ney Matogrosso em Secos \& Molhados, Rita Lee no grupo Tutti Frutti e o grupo teatral DziCroquettes. Escandalizaram grande parte do público brasileiro em plena ditadura militar, com uma "guerrilha estética" (CONRAD, 2013), única resistência possível naquele devir:

[...] A performance de Secos \& Molhados, por sua vez, mesmo não tendo um interesse declaradamente político, como explicava Ney, atuava na desterritorialização de um tabu, sendo a sua existência em si um ato político. Por essa razão, a própria visualidade do grupo, enquanto imagens ativas do desejo provocava a insurreição de sentimentos latentes no público - fossem eles de empatia ou repulsa. Nesse ponto é importante destacar, novamente, o figurino do trio, que tinha papel essencial no impacto de sua apresentação (MULLER, 2017, p. 256). 
"O discurso da performance é o discurso radical" (COHEN, 1989). As performances viscerais e o figurino andrógino traziam em seu bojo uma linguagem de afronta as sociedades decadentes e opressoras, como no caso do Brasil pós-golpe militar de 1964. Segundo Heloísa Buarque de Hollanda (1984), as manifestações da década de 70 fizeram-se visíveis já em 1968, com a decretação do Al-5, que anunciou um período caracterizado pelo silenciamento dos movimentos sociais e das artes em geral. Procurou-se, neste contexto, tentar entender o fracasso da juventude imersa na guerrilha, ou então, na loucura do "desbunde".

O chamado "desbunde" enquanto via alternativa, segundo Gonçalves (2008), foi aderida por pequena parcela da juventude coadunada com a contracultura.

[...] parte dos integrantes da geração anos 1970 - o que não exclui integrantes de outras gerações -, não reconheciam mais na militância política um ideal de vida a ser seguido e, em convergência com a liberalidade proposta pelos movimentos de contracultura, adotaram o desbunde como signo de rebeldia e descrença em relação aos projetos revolucionários e, de certo modo, também à ordem vigente (GONÇALVES, 2008, p.39).

É neste clima ideológico que combinava frustração, medo e desalento, que se formou a geração brasileira dos anos 1970 na qual despontou o estilo Glam, com representantes desde o estilo rock pop, passando pelo rock progressivo e o heavy metal, a exemplo.

O pioneiro do Glam Rock no Brasil foi o irreverente artista Edivaldo Souza, parceiro de Sérgio Sampaio e Raul Seixas, mais conhecido como Edy Star, considerado o pioneiro da militância gay que teve um único álbum gravado pela "Som Livre" em 1974, intitulado SweetEdy. Nele, faixas emblemáticas compostas por artistas como Jorge Mautner, Gilberto Gil, a exemplo. A primeira canção do disco, "Claustrofobia"", foi assinada por Erasmo e Roberto Carlos: "E dou vexame porque eu preciso de espaço / Quero respirar senão acabo no bagaço / Atravessando no compasso. Pare de me sufocar... Porque senão eu grito" e a faixa Bem Entendido: "Chega de brincadeira / já estamos bem entendidos / concubinados, convencidos / Que para um bom entendido 
/ Meia cantada basta". Na imagem abaixo, capa de seu álbum "Sweet Edy" (lançado em 1974), é perceptível a caracterização glam: indumentária extravagante e glamourizada, com luzes de neon desenhadas, plumas e paetês entre outros.

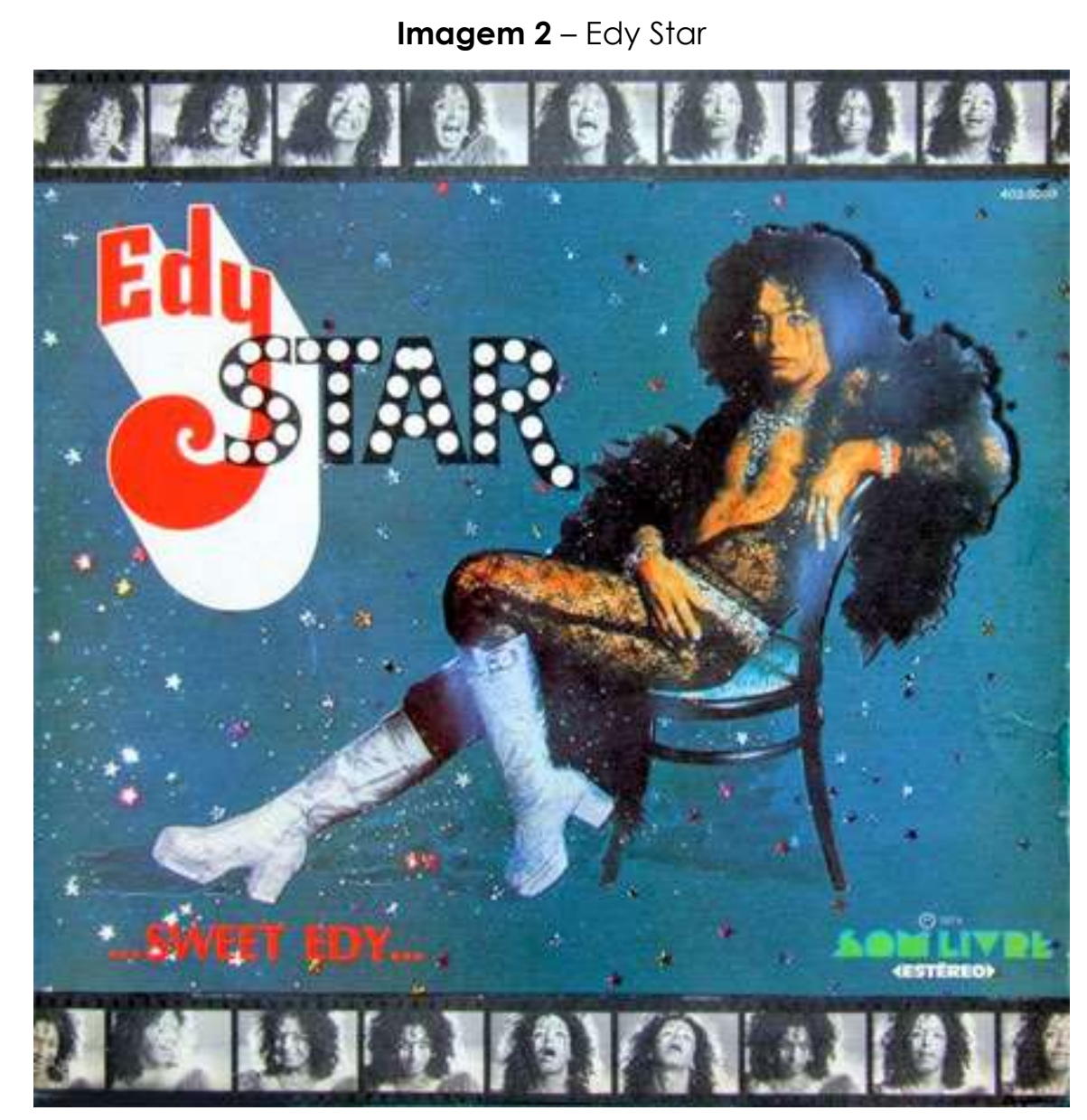

Fonte: Site do Poeira Zine

http://www.poeirazine.com.br/assunto/edy-star/

Seus shows performáticos em boates do Rio de Janeiro e de São Paulo, com figurinos e maquiagens exóticos, fizeram com que ganhasse visibilidade e em 1975, estrelou a primeira montagem brasileira do musical Rocky Horror Show, produzida por Rubens Corrêa.

O musical britânico que se tornou um ícone da cultura pop ganhou várias adaptações no mundo todo. Trata-se de uma homenagem bem humorada aos filmes $B$ de ficção científica e de terror do final da década de 1940 até o início da década de 1970, que conta a história de um casal 
conservador que pego em uma tempestade, buscam refúgio na casa de um travesti que era um cientista maluco. Justamente neste dia, o cientista deu vida ao seu mais novo invento: uma espécie de Frankenstein em forma de um homem musculoso, artificialmente fabricado, chamado Rocky Horror. A semelhança com o personagem de Bowie, ZiggyStardust, não é mera coincidência, pela duplicidade que carrega (homem e mulher). $\bigcirc$ referido Frankestein vive sua sexualidade de forma plena, seduzindo o casal e os transformando, desregrando-os frente aos ditames estabelecidos. $\bigcirc$ figurino glitter que o acolhe é um espartilho, sem seios e sunga marcando sua genitália proeminente. Na imagem abaixo, Edy Star de forma irreverente, protagoniza o Frank-n-Furter na montagem da peça traduzida no Brasil por Jorge Mautner.

Imagem 3 - Cena de Rock Horror Show (Brasil, 1975) 

na década de 1970. Domínios da imagem, v. 13, n. 25, p. 65-88, jul./dez. 2019.

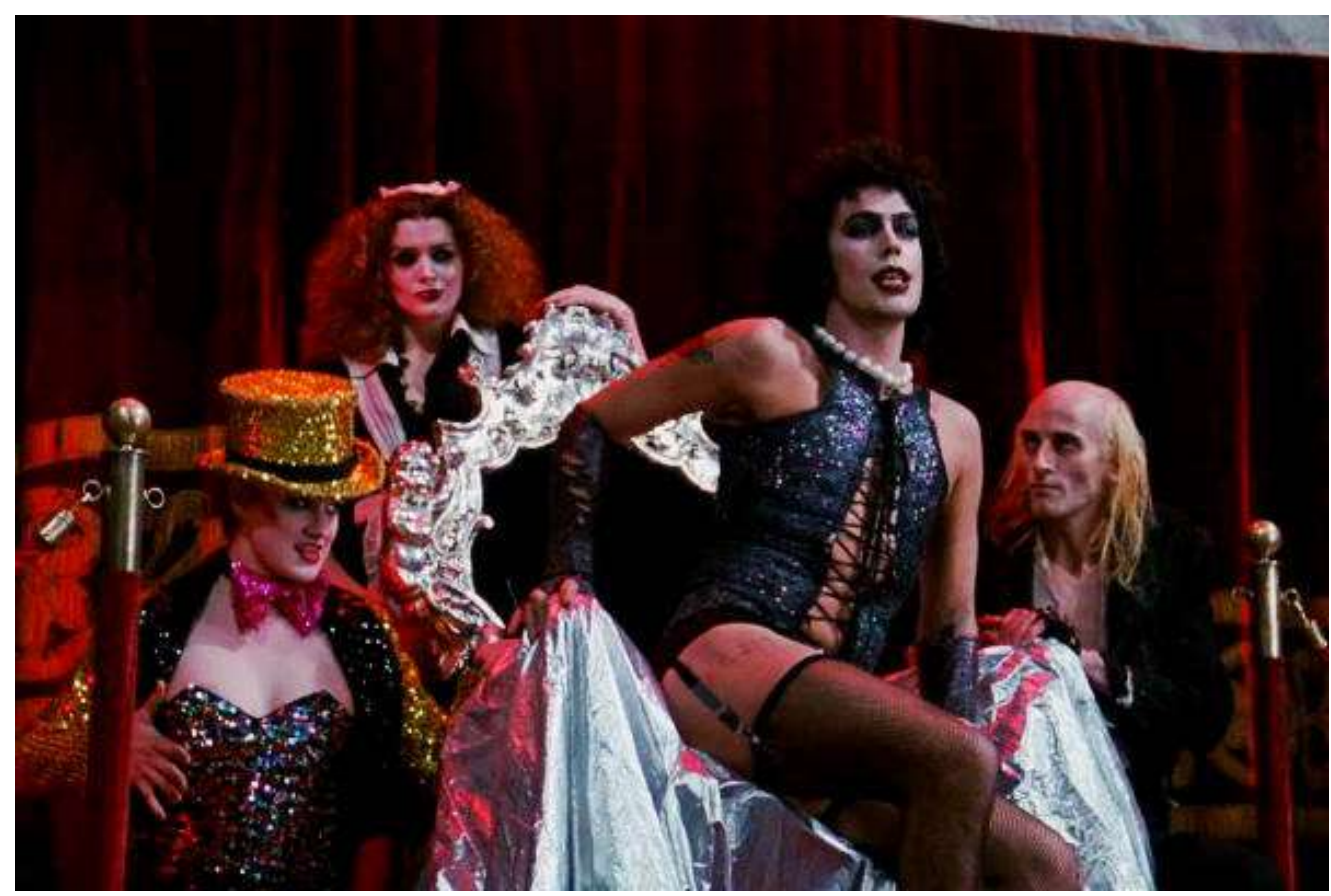

Fonte: Site do Plano Crítico

https://www.planocritico.com/critica-the-rocky-horror-picture-show-1975/

O grupo DziCroquettes, outro representante da estética Glam no teatro, realizou seu primeiro show em maio de 1973, em São Paulo, com um visual característico: cílios postiços, purpurinas, plumas e pernas peludas sob saias, vestidos de mulheres e trajes minúsculos (MOREIRA, 2010). A peça intitulada: "Andróginos: gente computada como você", contava com treze participantes: Wagner Ribeiro de Souza, Lennie Dale, Claudio Gaya, Claudio Tovar, Ciro Barcelos, Reginaldo de Poli, Bayard Tonelli, Rogério de Poli, Paulo Bacellar, Benedictus Lacerda, Carlos Machado, Eloy Simões e Roberto de Rodrigues: "Nem senhores, nem senhoras/ Gente dali, gente daqui/ Nós não somos homens, também não somos mulheres/ Nós somos gente [...] gente computada igual a você" (Documentário, 2009). Na metade do ano, o grupo sofreu a censura pela ditadura devido ao uso do nudismo no espetáculo. Depois de trinta dias foi autorizada com pequenas modificações na vestimenta dos seus integrantes (TOLEDO, 2015, p. 8). 

na década de 1970. Domínios da imagem, v. 13, n. 25, p. 65-88, jul./dez. 2019.

contra a ditadura e em quem operava a favor dela. Como justificar uma censura sobre um modo de fazer arte que não ataca explicitamente o poder dos militares no governo naquela ocasião? Como apoiar um grupo de artistas que está rotulado por posturas dogmáticas como um bando de drogados e alienados? Qualquer rótulo, vindo dos militares ou vindo dos militantes de esquerda, não apreendia outra revolução, aquela que se fazia no âmbito da micropolítica, desencadeada na fronteira entre o poder e o desejo (TOLEDO, 2015, p. 8).

Imagem 4 - DzyCroquettes

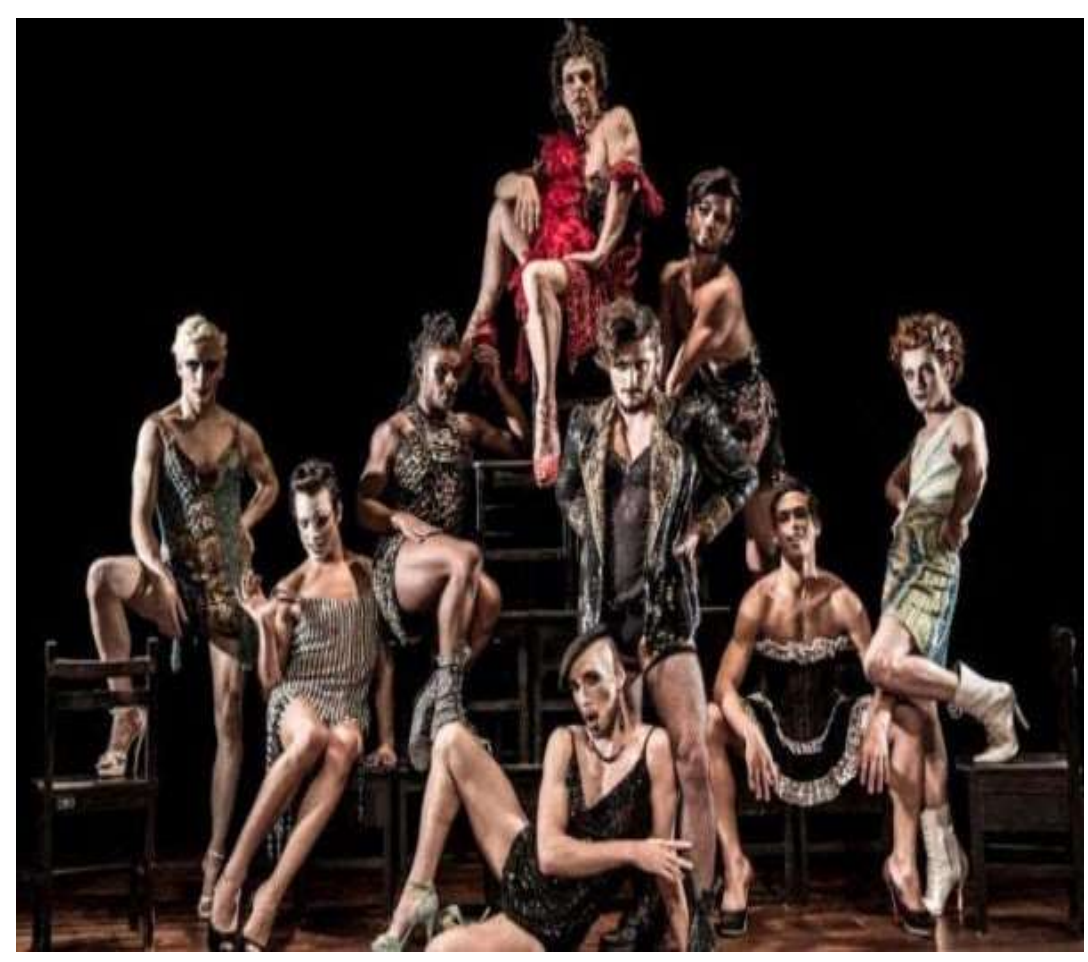

Fonte: https://www.diariodocentrodomundo.com.br/dzi-croquettes-o-grupo-deteatro-mais-transgressor-do-brasil-em-tempos-de-temer-e-trump-por-zambarda/

O trio musical paulista, Secos e Molhados, lançou seu álbum de estreia em 1973. O destaque era o cantor Ney Matogrosso que utilizava linguagens cênicas e musicais nunca vistas antes, agregando teatro, música brasileira, rock, folclore português, poesia, androginia e críticas à ditadura (Maus, 2016, p.47). Aliás, o próprio show encerrava-se em si mesmo como uma provocação:

[...] figura altiva (peito nu estufado e cabeça erguida) mesmo de pés descalços, os olhos são arregalados, a voz aguda é marcante, movimentos exagerados da boca marcam a 
pronúncia das palavras, movimentos de quadris insinuam outros códigos, penas, colares e lantejoulas bailam com o corpo, séries de movimentos de dança ou completamente livres sobre o palco transformaram-se em códigos de desprendimento. Não eram movimentos ensaiados e sempre iguais. Nas criações, o improviso, a criatividade e a liberdade eram seguidas espontaneamente pelos três. No início, o uso da maquiagem apareceu um pouco por acaso (VARGAS, 2010, p.11).

Imagem 5 - Grupo Secos e Molhados

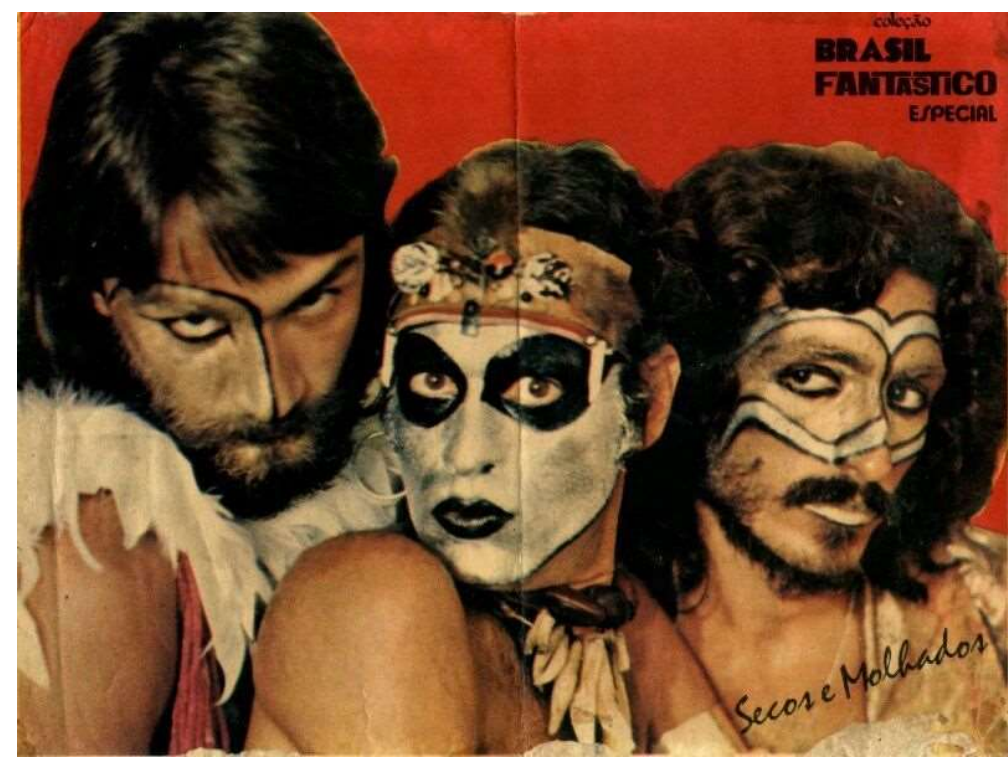

Fonte:https://aminoapps.com/c/m-lets-rock-m/page/item/secosmolhados/IXWY_aYLFGIDXr2nJYvWZYVKG7XYvE2nKje

Maquiagem exótica, roupas demarcando e colocando o corpo em evidência através de dança andrógina, fazia parte da encenação produzida pelo grupo que marcou uma geração.

A Moda Glam brasileira nos traz elementos importantes para 0 entendimento dos processos de identificação e diferenciação de grupo que inferem muitas interpretações do comportamento social e da relação entre gostos e roupas. A aparência e a indumentária expressam o sentimento de pertencimento a uma tribo, estreitando os laços entre os jovens de todo o mundo, diferenciando-os de outros segmentos sociais em termos comportamentais, políticos e estéticos. Os movimentos contraculturais expressos através de uma antimoda ganharam visibilidade pós-Segunda Guerra Mundial, com nuanças específicas em cada lugar onde se 
estabeleceram com ideais, valores e concepções de existência radicalmente opostos aos padrões vigentes (CALANCA, 2008). Estabelece, segundo Maffesolli (1996), um sentimento tribal com a sensação comum de pertencimento (designado como estética), com o laço coletivo de empatia (ética) e com o resíduo que fundamenta o "estar junto" (o costume). A prática cultural desruptiva ancorada numa estética da bricolagem, do excesso e da descontinuidade observada, segundo Connor (citado por Cidreira, 2009, p.03), sustenta-se sob a égide do desafio a um conjunto de normas culturais dominantes ou oficiais e comprometidas que, por sua vez, anulam a possibilidade da diversidade. Segundo Cidreira (2008, p. 37), o que permite e cria as condições da própria política da diversidade que defende esse tipo de prática cultural de resistência é muito mais um afrouxamento da pressão de uniformidade autoritária.

No Brasil, na década de 70, a possibilidade de ser híbrido por si já era uma forma de contestação à cultura dualista vigente. Por meio do humor, sarcasmo, exagero nas vestes, cabelos e maquiagens, danças e apresentações que exalavam de forma explícita a sexualidade andrógina, delineavam-se formas de resistência diferenciadas frente à ditadura militar. $\bigcirc$ caminho "era pelas brechas" (grifo nosso): metáforas ("corpo-palavra"), rock, seres andróginos, plumas e paetês. Como postula o poeta Ricardo Chacal: "já que é proibido pisar na grama, o jeito é deitar e rolar".

\section{Considerações Finais}

Essas crianças em quem você cospe/ Enquanto elas tentam mudar o mundo/ São imunes às suas consultas/ Estão muito cientes do que enfrentam. Changes (David Bowie)

Cabeças cortadas sobre a mesa. Corpos seminus nos palcos (enquanto corpos completamente nus eram estraçalhados nos porões), menestréis que faziam da nostalgia da beleza a sua arma naquela guerra suja: uma rosa de Hiroshima "sem cor sem perfume sem rosa sem nada" (CONRAD, 2013, p. 8).

Buscou-se por meio da presente pesquisa (em fase inicial), analisar os significados da androginia no Glam Rock e suas expressões no campo da Moda e comportamento nas décadas de 70 e 80, no Brasil. Sobre o Glam, Luiz 
Carlos Maciel publica na revista Rock: A História e a Glória (1976), uma reflexão sobre aquilo que chamou de terceira geração do rock, suas derivações e seus significados sociais:

[...] enquanto se difunde e se assimila a experiência da expansão da consciência dos anos 60, são a experiência mística (Mahavishnu) ou a psicótica Lou Reed que começam a caracterizar a vanguarda dos anos 70 . Essas últimas experiências são frutos das condições estabelecidas pela primeira. Na medida que passarem para o nível de assimilação e da difusão, poderão provocar modificações substanciais em nossa sociedade como um todo. Os marginais das classes altas adoram o glam rock: garotos exasperados das classes médias pra baixo ficam alucinados com os heavy metals; outros, mais sofisticados, mergulham em contemplação ao som do classic rock; jovens da alta burguesia, ainda cuidadosos das aparências, descansam com o bitter\&sweet; e uma nova consciência mística, inspirada na figura legendária de John Coltrane, sente-se próxima de Miles Davis e do Mahavishnu, John Mclaughlin. O rock, espelho de nosso tempo em sua totalidade [...] teria, assim, de refletir secretas mudanças sociais, que se insinuam lenta mas finalmente, em pequenos segmentos, no contra-jogo de um silêncio deliberado, em nosso corpo comum, isto é, social. Um exemplo típico desses inéditos movimentos sociais está encarnado no glam rock, esse "encontro dos filhos de boa família com os filhos do lixo", como disse Antônio Bivar. [...] O atual rock, nas suas diferentes manifestações, expressa essas novas realidades (MACIEL, 1976, p. 11).

A questão da mudança comportamental proposta pela contracultura hippie em relação à sexualidade foi de suma importância para o entendimento da androginia, percebida como a evolução da espécie, pois representou a ideia de transcendência da questão sexual binária, comumente normalizada. Foram inúmeros artigos publicados na imprensa alternativa internacional e brasileira sobre o tema, colocando a androginia como a mutação da espécie humana, segundo premissas advindas da contracultura hippie. Essa mutação pode ser vista por meio da mudança nos costumes, da relação diferenciada com o corpo, reverberadas a exemplo, na Moda unissex (AVELAR, 2011), que pode ser vislumbrada nas ruas até nos dias atuais. O gênero musical e estilo Glam Rock exponenciou o caráter andrógino, hedônico e narcísico da geração dos anos 70, notabilizando-se através de 
shows, performances, roupas e maquiagens extravagantes, proclamando a liberdade de ser e se vestir como quiser, sem as amarras normativas.

A força da imagem, da aparência e da indumentária são elementos importantes na solidificação de grupos específicos, constituindo-se em emblemas e símbolos significativos das transformações que os jovens almejavam. Segundo Rolland Barthes (2005), a Moda tem traços mundanos que são infinitos, inumeráveis e abstratos. A Contracultura, por sua vez, oferece também um horizonte de possibilidades, pois trata-se de um processo dinâmico que persiste atualmente, de forma diferenciada, por meio dos nichos contraculturais que, com seu hedonismo, transgridem 0 "estabelecido", conjugando a estética pós-moderna. Em meio aos escombros da pós-modernidade e da complexidade das relações sociais, políticas e culturais, a Moda Glam afirma-se como um produto a ser consumido; por outro lado, rompe com a hierarquia e uniformidade em busca da individualidade e originalidade, reinventando e estetizando a existência.

\section{Referências}

ANAZ, Sílvio. O que é Rock. São Paulo: Pop Books, 2013. 
ARRABAL, José. Anos 70: Momentos decisivos da arrancada. In NOVAES, Adauto (org). Anos 70: Ainda sob a tempestade. Rio de Janeiro, Aeroplano: Editora Senac, 2005.

AVELAR, Suzana. Moda: globalização e novas tecnologias. 2 ed. São Paulo: Estação das Letras e Cores, 2011.

BARROS, Patrícia Marcondes de. A Revolução Sexual nos anos 70 e o pensamento contracultural de Rosie Marie Muraro. Revista NUPEM, Campo Mourão, v. 9, n. 18, p. 98-108, set./dez. 2017. Acesso em 10/04/2020.

BARROS, Patrícia Marcondes de. Tropicália: contracultura, moda e comportamento em fins da década de 60. Revista Dobras, São Paulo, v. 9, n. 20, 2016. Disponível em:

https://dobras.emnuvens.com.br/dobras/article/view/482 Acesso em 10/04/2020.

BROWN, Norman O. Loves Body. New York: Vintage Books, 1966.

BROWN. A vida contra a morte: o sentido psicanalítico da História. Tradução de Nathanael C. Caixeiro. Petrópolis: Vozes, 1972.

BARTHES, Rolland. Imagem e moda. Inéditos. v.3. São Paulo: Martins Fontes, 2005.

CALANCA, Daniela. História Social da Moda. São Paulo: Senac, 2008.

CIDREIRA, Renata Pitombo. A Moda nos anos 60/70: comportamento, aparência e estilo. Recôncavos: Revista do Centro de Artes, Humanidades e Letras. vol. 2, no.1, 2008, p.35-44.

CIDREIRA, Renata Pitombo. Estilo, Moda e Consumo: Por uma poética do precário. In V ENECULT - Encontro de Estudos Multidisciplinares em Cultura, 2009, Salvador. Anais do quinto Encontro de Estudos Multidisciplinares em Cultura. Salvador: UFBA, 2009. Disponível em:http://www.cult.ufba.br/enecult2009/19637-4.pdf Acesso em: 01/10/2019.

COHEN, Renato. Performance como linguagem. São Paulo: Perspectiva, 1989.

CONRAD, Gerson. Meteórico fenômeno. São Paulo: Anadarco, 2013.

Documentário DziCroquettes será apresentado no Bosque do Sesc Thermas. Gl Globo.com. Disponível em: http://gl globo.com/sp/presidente-prudenteregiao/noticia/2016/07/documentario-dzi-croquettes-e-apresentado-no-cinebosque-dialogos.html Acesso em: 9 out. 2019.

DIAS, Lucy. Anos 70: enquanto corria a barca. Editora Senac São Paulo, 2003. 
GOFFMAN, Ken; JOY, Dan. A contracultura através dos tempos: do mito de Prometeu a cultura digital. Trad. Alexandre Martins. Rio de Janeiro: Ediouro, 2007.

GONÇALVES, Daniel José. O desbunde como manifestação política: a identidade de gênero na obra de Ana Cristina César. 2008. Dissertação (Mestrado em Estudos Literários). Universidade Federal do Paraná. Curitiba, 2008.

GRUDA, Mateus Pranzetti Paul.Dândi e Flâneur: Modos de subjetivação da modernidade e os Mods ingleses. Revista Psicologia em Estudo, Maringá, v.22, n. 4, p.517-527, out/dez. 2017.

HOLLANDA, Heloísa B. e GONÇALVES, Marcos A. Cultura e participação nos anos 60. $3^{a}$. edição. São Paulo, Brasiliense, 1984.

JARY. Homem não é homem, mulhomem. Mulher não é mulher, homulher (entrevista com Rose Marie Muraro). Bondinho, São Paulo, p.45, abr. 1972.

LIPOVETSKY, Gilles. O Império do efêmero: a moda e seu destino nas sociedades modernas. São Paulo: Companhia das Letras, 2009.

MACIEL, Luiz Carlos. A perfeição do andrógino. Flor do Mal, Rio de Janeiro, $5^{a}$. Ed., p.11, 1971.

MACIEL, Luiz Carlos. Terceira Geração. Rock: A História e a Glória, Rio de Janeiro, n. 15, p. 11, 1976.

MAFFESOLI, Michel. No fundo das aparências. Tradução: Nizia Villaça. Rio de Janeiro, Editora Vozes Ltda, 1996.

MAUS, Stephan. Necessidades e desejos de um corpo andrógino: um olhar no vestuário de Moda. 2016. Dissertação de Mestrado em têxtil e Moda. Escola de Artes, Ciências e Humanidades, Universidade de São Paulo, São Paulo, 2016.

MICK TED, Bowiemania. Revista Rolling Stone. Rio de Janeiro, p. 9, ano 1, 1972.

MOREIRA, Júlia. DziCroquettes: A história do polêmico grupo é relembrada e eternizada em documentário premiado. 2010. Disponível em:

http://revistadehistoria.com.br/secao/reportagem/dzi-croquettes. Acesso em 19 set.2017.

MULLER, Luiza. A guerrilha estética de secos e molhados como semiótica micropolítica. Temática, Paraíba. v.13, n. 3, p.250-267. Mar.2017. Disponível em 
BARROS, Patrícia Marcondes de. O Glam Rock brasileiro: moda e comportamento andrógino na década de 1970. Domínios da imagem, v. 13, n. 25, p. 65-88, jul./dez. 2019.

http://www.periodicos.ufpb.br/ojs/index.php/tematica/article/view/33409/17 283 Acesso em: 01/10/2018.

MURARO, Rose Marie. Feminismo e Androginia. Rolling Stone, Rio de Janeiro, $n^{\circ}$ 03. Fev.1972, p.06-07.

ENTENDA MELHOR-David Bowie- "The Rise and Fall of Ziggy Stardust". Site Plano Crítico. Pará, 14 de novembro de 2015. Disponível em:

http://www.planocritico.com/entenda-melhor-the-rise-and-fall-of-ziggystardust-david-bowie/ Acesso em: 19 set. 2017.

PINEDA, Dailza. Operação Ensaio: Por uma estética da resistência. TransForm. Psicol. (Online), São Paulo, v. 3, n. 1, 2010. . Disponível em:

http://pepsic.bvsalud.org/scielo.php?script=sci_arttext\&pid=\$2176106X201000 0100003\&lng=pt\&nrm=iso Acesso em: 8 out. 2018.

PIVA, Roberto. Roberto Piva: um paulistano desvairado. Revista Rolling Stone, Rio de Janeiro, 3 ed., 29 fev.1972, p. 13.

RILKE. Cartas a um jovem poeta. Flor do Mal, Rio de Janeiro, jun.1971SINGER, June. Androginia: rumo a uma nova teoria da sexualidade. São Paulo: Cultrix, 1990.

TOLEDO, Ricardo Emílio. Corpo e cultura: um estudo sobre a arte do grupo "DziCroquettes". 2015. 99f. Trabalho de Conclusão de Curso(Educação Física). UNESP, Rio Claro, 2015.

VARGAS, Herom. SECOS \& MOLHADOS: experimentalismo, mídia e performance. In XVIII Encontro da Compós, 2010, Rio de Janeiro. Anais do XVIII Encontro da Compós. Rio de Janeiro, PUC-Rio, 2010.

VICENTE, Gil. Ser criança, namorar, passear. Flor do Mal, Rio de Janeiro. 1 ed., p. $9,1971$.

\section{Filme e documentários}

VELVET Goldmine. Produção: Christine Vachon; Michael Stipe. Suécia. 1998. 1 bobina cinematográfica (2h7m), son., color.

DZI Croquettes. TRIA Productions, Canal Brasil. Direção e roteiro Tatiana Issa e Raphael Alvarez. 2009. Brasil. p\&b / cor, 110 min.

\section{Músicas}

Tyrannosaurus Rex. Children Of The Revolution. Children of the Revolution [Inglaterra]. EMI, 1972. 

na década de 1970. Domínios da imagem, v. 13, n. 25, p. 65-88, jul./dez. 2019.

Erasmo e Roberto Carlos. Claustrofobia. SweetEdy. [Brasil]. Som Livre, 1974

Piau e Sérgio Natureza. Bem entendido. SweetEdy. [Brasil]. Som Livre, 1974.

\section{Teatro}

The Rocky Horror Picture Show (Reino Unido, EUA, 1975)

Direção: Jim Sharman

Roteiro: Jim Sharman, Richard O'Brien (baseado em seu musical teatral)

Elenco: Tim Curry, Susan Sarandon, Barry Bostwick, Richard O'Brien, Patricia Quinn, Nell Campbell, Jonathan Adams, Peter Hinwood, Meat Loaf, Charles Gray, Jeremy Newson

Duração: 100 min.

The Rocky Horror Picture Show (Brasil, 1975)

Direção e roteiro: Rubens Corrêa

Elenco: Eduardo Conde, Wolf Maya, Lucélia Santos,Tom Zé.

Duração: 100 min. 